\title{
Duch Dziejów i uroki parytetu. O recepcji polskiej poezji w Szwecji po 1989 roku
}

\author{
Spirit of the Age and the Charm of Gender Parity. On the Swedish Reception of \\ Polish Poetry After 1989
}

Abstract: The article deals with the changes that have been occurring in the reception (both translational and critical) of Polish poetry in Sweden since the 1980s. It points to the break with reading Polish poetry in the historical and political contexts (that were the dominant "style of reception" for several decades) and abandoning the order of literary history for the anthropological perspective. Analysis of examples shows that since the 1990s Swedish literary criticism was clearly seeking new ways of accentuating the independence of reviewed Polish authors from the "historical" background (e.g., the case of Adam Zagajewski but also of Tadeusz Różewicz). The context into which Polish poetry is successfully and very consequently inscribed in contemporary Sweden is the feminist perspective, which is rooted in the long-time tradition of taking up "the plight of women" in Sweden (or, more broadly, in all of Scandinavia) and clearly visible also in Swedish research in literary history pertaining to Polish literature that were conducted during the last three decades. The poetry of Polish female poets is currently the subject of intense focus of Swedish critics and translators.

Keywords: reception of Polish literature abroad, translator as canon-maker, Polish literature in Sweden

Streszczenie: Artykuł omawia zmiany, jakie od drugiej połowy lat osiemdziesiątych XX wieku zachodzą w recepcji (translatorskiej i recenzenckiej) polskiej poezji w Szwecji. Wskazano w nim na odejście od lektury liryki polskiej w kontekście historycznym i politycznym (co było dominującym „stylem recepcji” przez całe dziesięciolecia) i porzucenie ujęć w porządku historycznoliterackim na rzecz perspektywy antropologizującej. Analiza przykładów wskazuje, że od lat dziewięćdziesiątych XX wieku szwedzka krytyka wyraźnie poszukuje sposobów na zaakcentowanie niezależności omawianych przez siebie polskich autorów od „dziejowego” tła, na jakim się plasują (między innymi przypadek Adama Zagajewskiego, a także Tadeusza Różewicza). Kontekstem, w jaki z powodzeniem i bardzo konsekwentnie wpisywana jest współcześnie w Szwecji polska poezja, jest perspektywa feministyczna, zakorzeniona zapewne w długiej tradycji podejmowania „kwestii kobiecej” 
w Szwecji (szerzej: Skandynawii), a wyraźnie obecna również w szwedzkich badaniach historycznoliterackich dotyczących literatury polskiej prowadzonych w okresie ostatnich dwudziestu kilku lat. Poezja polskich poetek jest w tej chwili przedmiotem bacznej uwagi szwedzkich tłumaczy i komentatorów.

Słowa kluczowe: recepcja literatury polskiej za granicą, tłumacz jako twórca kanonu, literatura polska w Szwecji

Recepcja liryki polskiej w Szwecji, dokonująca się za sprawą przekładów, refleksji krytycznej oraz badań literaturoznawczych to zjawisko na tyle intensywne, że bywało już przedmiotem systematycznego opisu ${ }^{1}$. Widziana z perspektywy szwedzkiej polska poezja reprezentuje nie tylko „duży” język, ale przede wszystkim niezwykle istotną tradycję („Niewiele krajów w naszym sąsiedztwie ma tak silną tradycję liryczną, jak Polska” - napisała niedawno we wstępie do antologii polskiej poezji najnowszej Irena Grönberg ${ }^{2}$ ), nadto poezja kojarzona z kulturą jakoś jednak bliską, z którą Szwecję wiele łączy (na dobre i na złe, ale bardzo intensywnie - o czym zdaje się świadczyć tytuł wydanej w 2019 roku popularyzatorskiej książki historycznej Sverige-Polen: 1000 àr av krig och kärlek [Szwecja-Polska: tysiąc lat wojny i mitości] wydanej przez znane wydawnictwo Albert Bonniers). Zarazem Szwecja i Polska to kraje, których literatury w perspektywie europejskiej, ale i światowej, mają charakter raczej peryferyjny. Do tłumaczeń na szwedzki polska literatura nie aspiruje więc w podobny sposób jak do przekładów na monopolizujący światową kulturę angielski (choć szwedzki przekład to tradycyjna droga do Nobla); relacja polsko-szwedzka jest w tym względzie bardziej, by tak rzec, egalitarna. Nie występuje tu (aż taka) niewspółmierność, jak ta opisywana na linii przekładów między językami angielskim i polskim przez Aleksandrę Kremer. Ta obustronna „peryferyjność” sprawia, że nie sposób (poza może okresem Młodej Skandynawii i Młodej Polski) uprawiać w badaniach „wpływologii”, toteż komparatystyka polsko-szwedzka wyraźnie koncentruje się w ostatnich latach nie na ujęciach historyzujących, lecz antropologizujących ${ }^{3}$ - a konsekwencje takiej optyki badawczej w formowaniu się obrazu najnowszej poezji polskiej w Szwecji są, jak postaram się wykazać, dalekosiężne.

Zasadnicza różnica między społecznym doświadczeniem Polaków i Szwedów w XX wieku to fakt, że Szwecja - jak wiadomo - pozostała neutralna podczas obu wojen światowych, a po 1945 roku uplasowała się poza główną osią

1 Por. zwłaszcza: A.N. Uggla, Polska liryka w Szwecji po roku 1939, „Slovo. Journal of Slavic Languages, Literatures and Cultures" 1981, nr 20, s. 42-66; M.A. Packalén, Polska poezja wspótczesna w Szwecji, „Polonistyka” 1999, nr 2, s. 111-113; M.A. Packalén Parkman, „Niektórzy lubia poezje” - ale czy koniecznie polska i w Szwecji?..., „Slovo. Journal of Slavic Languages, Literatures and Cultures" 2017, nr 58, s. 39-49.

2 I. Grönberg, Förord [w:] 17 polska poeter, red. I. Grönberg, Stockholm 2003, s. 7, tłum. K.S.H.

3 Zob. M.A. Packalén, Under två kulturers ok. Allmogeskildringar i den polska och svenska 1880- och 1900-talslitteraturen, Uppsala 2001. 
konfliktów zimnowojennych. Zwłaszcza obserwowana z takiej perspektywy stojącego na uboczu świadka, który szczęśliwie uniknął zagrożenia i tragicznego losu ofiary - polska historia jawi się jako szczególnie bolesna, a polska literatura jako pełna wątków, które dla Szwedów pozostawały obce. Taka optyka pozostaje w mocy także w dokonywanych obecnie diagnozach poezji polskiej „z lotu ptaka”. Znamienne są słowa Petera Handberga, tłumacza poezji Aleksandra Wata, który w przedmowie do niedawno wydanego tomu zanotował:

Polska literatura XX wieku to wiele znaczących nazwisk. Prócz prozaików i dramaturgów - Witolda Gombrowicza, Bruno Schulza, Stanisława Ignacego Witkiewicza, Jerzego Andrzejewskiego, po późniejszych, Sławomira Mrożka i Andrzeja Szczypiorskiego, wymienić należy poetów: Tadeusza Różewicza, Zbigniewa Herberta, Adama Zagajewskiego i dwoje noblistów - Czesława Miłosza i Wisławę Szymborską.

Gdyby to stulecie - to, co zasadniczo należy do tego stulecia (...), czyli w okresie trzech czwartych całego wieku, jeśli chodzi o ścisłość - gdyby to stulecie opisać za pomocą doświadczenia wymienionych pisarzy, powinno się to zrobić wedle scenariusza: wojna, wykorzenienie, wygnanie, samobójstwo, masowe mordy, ucieczka, uwięzienie, deportacja, cenzura - $\mathrm{i}$ tak dalej...

To oczywiście historia zawężona, historia Polski - ale może raczej powinno się powiedzieć: widziana z polskiej perspektywy, gdyż ta „historia” dotyczy nas wszystkich, niezależnie od tego, jaka flaga powiewa na budynkach rządowych czy w ogródkach mieszkańców ${ }^{4}$.

Takie spojrzenie na literaturę polską - przez pryzmat historii narodowej jest zjawiskiem bardzo wyrazistym i silnie zakorzenionym (co nie bez sarkazmu komentowała szwedzka slawistka Małgorzata Anna Packalén Parkman, utrzymując, że w obiegu krytycznoliterackim schemat „narodowoojczyźniany" w komentarzach do dzieł polskich autorów do dziś zajmuje pozycję naczelną $\left.{ }^{5}\right)$ Z pewnością było ono dominujące jeszcze u progu lat osiemdziesiątych, kiedy Andrzej Nils Uggla pisał:

Zainteresowanie narodową problematyką polską, życiem kulturalnym i literaturą było w Szwecji zawsze, mniej więcej, zależne od sytuacji politycznej, w jakiej kraj się aktualnie znajdował. Zainteresowanie to pobudzały wstrząsające Polską kataklizmy, jak zakończone klęskami powstania narodowe, wojny lub, jak to miało miejsce w historii najnowszej, kryzysy polityczne ${ }^{6}$.

4 P. Handberg, Förord [w:] A. Wat, Bokslut, wybór, tłum. P. Handberg, Stockholm 2006, s. VII, tłum. K.S.H.

5 M.A. Packalén Parkman, „Niektórzy lubia poezję” - ale czy koniecznie polską i w Szwecji?..., dz. cyt., s. 39-49.

6 A.N. Uggla, dz. cyt., s. 42. 
Zjawisko zainteresowania literaturą polską na fali śledzenia rozgrywających się w Polsce wydarzeń politycznych miało swoje zaskakujące efekty w postaci błyskawicznej recepcji pewnych dzieł literackich - tych właśnie „politycznie” istotnych. Niekiedy natychmiastowość reakcji tłumaczy i powstania przekładów jest doprawdy zdumiewająca (na przykład już w 1956 roku przełożono na szwedzki fragmenty Poematu dla dorostych Adama Ważyka i Październik 1956 Juliana Przybosia). O ile w latach pięćdziesiątych import polskich wierszy miał jeszcze charakter nieco przypadkowy, o tyle od lat sześćdziesiątych powstały pierwsze ważne przekłady poetów polskich, którzy w tym samym czasie zdobywali popularność w kręgu anglojęzycznym. Podobnie jak w opisywanym przez Kremer obiegu literackim w Stanach Zjednoczonych również w Szwecji przez dziesięciolecia mniej popularna była poezja Tadeusza Różewicza niż Czesława Miłosza czy - zwłaszcza - Zbigniewa Herberta. W 1960 roku ukazała się w Szwecji antologia polskiej poezji Det nakna ansiktet [Naga twarz] zredagowana przez Nilsa Åkego Nilssona, w której znajdują się wiersze Ważyka (właśnie Poemat dla dorostych), Różewicza, Herberta, Jerzego Ficowskiego, Bohdana Drozdowskiego, Jerzego Waleńczyka, Stanisława Czycza, Ireneusza Iredyńskiego, Mieczysławy Buczkówny, Wisławy Szymborskiej i Arnolda Słuckiego?

W szwedzkiej recepcji powojennej poezji polskiej istnieje jeden przypadek nieco pokrewny opisanemu przez Justina Quinna „casusowi Holuba”, choć rozziew między recepcją na gruncie rodzimym i obcym nie jest tak przepastny, jak to było w pouczającej historii opowiadanej przez irlandzkiego badacza. Niemniej pozostaje symptomatyczny. Spośród poetów pokolenia 68 (które skądinąd stało się obiektem należnej badawczej uwagi ze strony szwedzkiej polonistyki ${ }^{8}$ ) jedynym właściwie twórcą obszernie tłumaczonym na szwedzki i dostrzeżonym przez tamtejszą opinię krytyczną jest Adam Zagajewski („własnych" książek po szwedzku doczekała się prócz niego jedynie Ewa Lipska, i to dużo później - w 1997 wydany został tom jej utworów z lat 1970-1994 pt. Zon [Zona] w przekładzie Andersa Bodegårda, a w 2015 Kära fru Schubert [Droga Pani Schubert] w przekładzie Grönberg). „Dostrzeżony” to zbyt mało: jak pisze Packalén Parkman, Zagajewski „zaistniał na większą skalę na szwedzkim forum literackim i wymieniany jest nawet od kilku lat jako kandydat do nagrody Nobla"9. Oczywiście, także w Polsce Zagajewski pozostaje poetą znanym i cenionym, choć trudno chyba byłoby dowodzić, że całkowicie zdystansował w czytelniczej i badawczej recepcji innych twórców swego pokolenia, choćby Stanisława Barańczaka, Lipską czy Ryszarda Krynickiego.

7 O recepcji tej antologii pisze obszernie Andrzej Nils Uggla - zob. tamże, s. 53-56.

8 Autorką ważnego opracowania na temat Nowej Fali jest wielokrotnie wspominana już przeze mnie uppsalska literaturoznawczyni Małgorzata Szulc Packalén - por. tejże, Pokolenie 68. Studium o poezji polskiej lat siedemdziesiatych, Uppsala 1987.

9 M.A. Packalén Parkman, „Niektórzy lubia poezje” - ale czy koniecznie polską i w Szwecji?..., dz. cyt., s. 43 . 
Jakie były koleje szwedzkiej recepcji twórczości Zagajewskiego? Jej początek to publikacja tomu Ode till mångfalden och andra dikter [Oda do wielości i inne wiersze] w przekładzie Bodegårda i Larsa Kleberga w 1987 roku, choć może na miejscu byłoby raczej wskazać, że osoba pisarza-emigranta często pojawiała się już w pierwszej połowie lat osiemdziesiątych na łamach szwedzkiej prasy ${ }^{10}$, a w 1985 roku pisarz otrzymał stypendium literackie im. Kurta Tucholsky'ego, przyznane przez szwedzki PEN Club. To postrzeganie Zagajewskiego jako pisarza-emigranta ze zniewolonego kraju Europy Środkowej znalazło wyraz we wczesnym, bo wydanym już w 1988 roku (a więc dwa lata po ukazaniu się oryginału), przekładzie Solidarności i samotności dokonanym przez Bodegårda i Martina von Zweiberga. Od lat dziewięćdziesiątych Zagajewski był już na tyle w Szwecji rozpoznawalny, że ukazały się szybko kolejne tomy, wszystkie w wyborze i przekładzie Bodegårda: Elektrisk elegi och andra dikter [Elektryczna elegia i inne wiersze] (1993), Törst [Pragnienie] (2003), Antenner i regn [Anteny w deszczu] książka zawiera wiersze z trzech tomów, które wydano w pierwszym dziesięcioleciu XX wieku: Powrót, Anteny i Niewidzialna ręka (2011), ten ostatni z posłowiem szwedzkiej poetki Marie Lindquist ${ }^{11}$. W tym czasie pojawiły się też tłumaczenia prozy Zagajewskiego (dokonane również przez Bodegårda): Två städer [Dwa miasta] (1991) oraz I andras skönhet [W cudzym pięknie] (2015). Obraz ten wciąż nie będzie kompletny, jeśli pominie się fakt, że w latach 20002019 ukazały się po szwedzku aż trzy książki „czytane” autorstwa Zagajewskiego: prozatorskie Två städer oraz dwa tomy poezji wcześniej wydane w formie książkowej (Elektrisk elegi och andra dikter oraz Antenner i regn).

Trudno się dziwić, że w przytoczonej wcześniej, niedawnej wypowiedzi Handberga Zagajewski wymieniony został jednym tchem obok „wielkiej

10 Por. wyniki wyszukiwań w archiwum jednego z największych szwedzkich dzienników, „Dagens Nyheter”: w latach 1980-1985 Zagajewski występuje na łamach tej gazety kilkanaście razy. Tę (dość jednak zaskakująca) popularność należy widzieć w kontekście sytuacji politycznej i społecznej w Polsce oraz fali emigracji politycznej z PRL. Należy pamiętać, że w tym samym okresie znalazło się w Szwecji w charakterze migrantów kilka tysięcy Polaków. To w takich właśnie okolicznościach ukazała się książka Du måste vittna. Poesi och reportage från Polen [Musisz dać świadectwo. Poezja i reportaże z Polski] w opracowaniu Nilsa Åkego Nilssona (Stockholm 1981), gdzie znalazły się teksty Miłosza, Szymborskiej, Herberta, Barańczaka, Krynickiego i Zagajewskiego, w pewnej mierze analogiczna do wydawanych w bezpośrednim kontekście drugiej wojny światowej antologii Det kämpande Polen [Polska walcząca] z 1942 roku (red. N. Żaba, M. Hansson) oraz Så länge vi leva. Polsk lyrik 1939-1945 [Póki my żyjemy. Polska poezja 1939-1945] wydrukowanej w czasopiśmie „Svio Polonica” w 1946 roku. Z kolei w latach 1984-1989 istniało nieregularnie ukazujące się czasopismo „Hotel Örnsköld. Polsk dikt och debatt" wydawane przez wydawnictwo Nordstedt, w którym publikowano literaturę polską w przekładach oraz wypowiedzi dotyczące sytuacji politycznej i społecznej w ówczesnej Polsce. Przykłady te znakomicie dokumentują bliskie sąsiedztwo literatury polskiej i polskiej polityki w ich szwedzkiej recepcji.

11 Notabene, przysługa nie pozostała nieodwzajemniona. Zagajewski napisał krótkie posłowie do polskiego wydania poezji Lindquist Pisane na kamieniach (tłum. Z. Kruszyński, Warszawa 2015). 
czwórki” polskich poetów dwudziestowiecznych, zaś w tekstach krytycznych jego nazwisko, pojawiające się w sąsiedztwie nazwisk Herberta i Różewicza, nie wymaga już dodatkowych wyjaśnień ${ }^{12}$. Liczba przekładów na szwedzki i proporcje przełożonych na szwedzki wierszy do całości dorobku poetyckiego są naprawdę imponujące, a miejsce Zagajewskiego w szwedzkim kanonie literatury polskiej - niekwestionowane i bardzo wysokie.

Wydaje się, że import wierszy Zagajewskiego do Szwecji należałoby widzieć na tle okoliczności nie tylko stricte literackich (i wrócić pamięcią do cytowanej wcześniej diagnozy Uggli, dotyczącej korelacji między wydarzeniami politycznymi w Polsce a recepcją polskiej literatury na szwedzkim gruncie). Zarazem nie sposób przeoczyć znamiennej tendencji pojawiającej się w wypowiedziach szwedzkich krytyków na temat Zagajewskiego już w latach osiemdziesiątych. Jego indywidualność jest konsekwentnie opisywana jako poszukiwanie „trzeciej drogi" dla poezji: pomiędzy porzuceniem jakichkolwiek odniesień do rzeczywistości a oddaniem pióra w „szlachetną niewolę” i służbę słusznej sprawie politycznej wolności. Zagajewski odnajduje, jak pisała Birgitta Trotzig, poezję, która „wychodzi ze stanu zniewolenia, z domu ideologicznej niewoli, na trzecią drogą: drogę doświadczeń sumienia, na pozbawiony ograniczeń szlak indywidualnego wyrazu"13. W podobnym duchu o liryce Zagajewskiego pisał Lars Kleberg, który dowodził, że:

zarówno w warunkach eksplodującej wolności, jak i następującego po niej, nasilonego zniewolenia, wzywano z różnych stron do tego, by poezja zaangażowała się w walkę ideową. W tej sytuacji dla Zagajewskiego pozostawało zupełnie jasne, że poezja, która ma za zadanie przemawiać na rzecz wolności, może łatwo stać się zaprzeczonym odbiciem języka swoich przeciwników i w ten sposób popaść w jeszcze głębsze zniewolenie. Jako znak protestu wobec tej sytuacji wyrosła nowa poezja Zagajewskiego: długie wiersze, łańcuchy zaskakujących obrazów i wiersze liryczne pełne głębokiej osobistej refleksji ${ }^{14}$.

Wydaje się, że z czasem powstało w krytyce szwedzkiej coś w rodzaju topiki wskazywania na „trzecią drogę”, na wyjątkowość tego czy innego polskiego twórcy na tle imperatywu działania i przemawiania w imieniu narodu opierającego się zniewoleniu (która to topika jest skuteczna o tyle, o ile odwołuje się jednocześnie do specyfiki polskiej historii w XX wieku oraz tradycji polskiej poezji, łatwo nakładającej na poetów szczególne dziejowe zobowiązania).

12 Por. I. Grönberg, Efterord [w:] T. Dąbrowski, Idag har jag àter hört tystnaden efter mig. Dikter, wybór, tłum. I. Grönberg, Malmö 2017, bns.

13 B. Trotzig, Att vara i mitten utan att gråta [w:] tejże, Porträtt. Ur tidshistorien, Stockholm 1993, s. 189, tłum. K.S.H.

14 L. Kleberg, Efterskrift [w:] A. Zagajewski, Ode till mångfalden och andra dikter, wybór, tłum. A. Bodegård, L. Kleberg, Norstedts, Stockholm 1987, s. 68, tłum. K.S.H. 
Bardzo charakterystyczne jest w tej mierze posłowie do wydanego w 2003 roku wyboru wierszy Różewicza pióra tłumaczki Catherine Berg (która wcześniej, w latach 1965-1980, przełożyła na szwedzki siedem dramatów Różewicza i kilka utworów prozatorskich). Posłowie Berg otwiera znamienne stwierdzenie:

O ile mi wiadomo, Tadeusz Różewicz raz tylko w swym życiu ogłosił polityczny protest wymierzony przeciw aktualnie rządzącej władzy. Miało to miejsce kilka lat temu: w wysłanym do prasy artykule zaoponował przeciwko zamierzeniom włodarzy miasta Wrocław, którzy planowali budowę dużego, szpetnego garażu w miejscu dokładnie naprzeciw balkonu poety.

Tak to już jest w Polsce: niekiedy się mówi, niekiedy milczy, a innym razem krzyczy ${ }^{15}$.

Dalej w posłowiu mowa jest o polskiej tradycji powstań narodowych (Berg używa sformułowania „det Obligatoriska Upproret” - „Obowiązkowe Powstanie”), łączącej kolejne pokolenia, i o domowym nauczaniu literatury i mitów narodowych (egzotyczne dla Szwedów opowieści o zebranych przy stole domownikach, uczących dzieci i młodzież języka i historii narodowej), które stanowią w optyce tłumaczki silnie kontrastowe tło twórczości Różewicza. Wskazuje to, z jednej strony, jak silnie osadzony był (i nadal pozostaje) w Szwecji kulturowy stereotyp polskiej poezji jako odzwierciedlenia ducha narodowego i niedoli ojczyzny. Z drugiej strony - na wyraźną potrzebę jego przełamania, jako niewyczerpującego tematyki polskiej poezji współczesnej. Znów przychodzi zacytować komentarz tłumaczy - słowa ze wstępu pióra Grönberg do antologii 17 polska poeter [17 polskich poetów] z 2003 roku: „Tym, co ich [poetów przedstawionych w książce - dop. K.S.H.] łączy, jest okoliczność, że ich sumień nie nękają myśli o ofiarach komunizmu w Polsce, w pewnym sensie zaczęli pisać w »roku zero"” 16 .

Przytoczone sformułowania wskazują, że od mniej więcej połowy lat osiemdziesiątych część środowiska pośredniczącego między polską literaturą a szwedzkimi czytelnikami odczuła najwyraźniej potrzebę zmiany stylu lektury polskich autorów - dotąd obciążonego wyjątkowo silnie analizą kontekstu politycznego $^{17}$. Nałożyły się na to zmiany w społecznym odbiorze Polski przez Szwedów. Przywołajmy raz jeszcze opinię Packalén Parkman:

15 C. Berg, Efterord [w:] T. Różewicz, Professorns kniv och andra dikter, wybór, tłum. C. Berg, J. Mizerski, Stockholm 2003, s. 179, tłum. K.S.H.

16 I. Grönberg, Förord, dz. cyt., s. 6, tłum. K.S.H.

17 M.A. Packalén Parkman, „Niektórzy lubią poezje” - ale czy koniecznie polską i w Szwecji?..., dz. cyt., s. 40 . 
Szwedzi bardzo długo pielęgnowali w świadomości społecznej wizerunek Polski jako kraju dopiero rozwijającego się - przez dziesięciolecia media prześcigały się w pokazywaniu niekończących się polskich kolejek, dymiących kominów czy wiejskiego ubóstwa. Wraz z upadkiem komunizmu Polska straciła trochę ze swojej egzotycznej otoczki ${ }^{18}$.

Pisarzem, którego twórczość niezmiennie czytana jest w kluczu historyczno-politycznym jest Herbert. Jego wiersze przekładane były na szwedzki wcześnie, bo już latach sześćdziesiątych ${ }^{19}$, a kolejna odsłona szwedzkiej recepcji dzieł autora Struny światta nastąpiła w gorących politycznie (i bardzo ważnych dla recepcji polskiej literatury w Szwecji) latach osiemdziesiątych ${ }^{20}$. Na kolejną edycję i nowe przekłady trzeba było czekać aż do roku 2013. Po przerwie prawie trzydziestoletniej od poprzedniego tomu (w którym to czasie pojawiły się po polsku trzy kolejne tomy liryków Herberta) i kilkanaście lat po śmierci poety ukazała się książka Inskrifter: valda dikter 1956-1998 [Napisy: wiersze wybrane z lat 1956-1998], zawierająca liryki wybrane i przełożone przez Grönberg. Tom ten jest najobszerniejszą prezentacją twórczości Herberta po szwedzku, a zaproponowany przez tłumaczkę klucz do dzieła poety jest - pomimo upływu czasu - w dużej mierze tożsamy z tym proponowanym we wcześniejszych edycjach. W posłowiu tłumaczka wyjaśnia, że tytuł - Inskrifter [Napisy] - to nawiązanie do ostatnich wersów wiersza Napis:

gdy wyschnie źródło gwiazd

będziemy świecić nocom

gdy skamienieje wiatr

będziemy wzruszać powietrze

Grönberg uważa je za najtrafniejszy komentarz do poezji Herberta, niejako streszczenie jej ducha, kulminującego - jej zdaniem - w Panu Cogito. Jak pisze: „Wiele liryków Herberta lśni niczym inskrypcje. Napisy poświęcone tym, którzy nie maja grobów, ofiarom wojny i dyktatury" ${ }^{21}$. Dokonany przez tłu-

18 Tamże, s. 42.

19 W 1965 roku ukazał się wybór wierszy zatytułowany I stridsvagnens spår: dikter 19561965 [Koleina wojennego wozu. Wiersze z lat 1956-1965] w bardzo dobrym przekładzie Erika Lindegrena i Erika Mestertona. O książce tej miałam okazję pisać obszerniej: K. Szewczyk-Haake, Ślad czotgu i sala zwierciadet. O spotkaniu dwóch poetów i ważkich decyzjach redaktorów, „Acta Sueco-Polonica” 2008-2009, nr 15, s. 45-60.

20 W 1985 roku ukazała się książka Rapport från en belägrad stad och andra dikter [Raport z oblężonego Miasta i inne wiersze] - autorami przekładów byli Agneta Pleijel oraz Maciej Zaremba (pseud. Daniel Bronski) przy współpracy Erika Mestertona.

21 I. Grönberg, Efterord [w:] Z. Herbert, Inskrifter: valda dikter 1956-1998, wybór, tłum. I. Grönberg, Lund 2013, s. 138, tłum. K.S.H. 
maczkę wybór wierszy odzwierciedla taki sposób czytania Herberta: najwięcej wierszy przełożono z tomów Hermes, pies i gwiazda oraz Pan Cogito; Epilog burzy reprezentują trzy utwory, Elegię na odejście - cztery, Rovigo - pięć (w tym trzy to szczególnie atrakcyjne z punktu widzenia międzynarodowej publiczności wierszowe dialogi Herbert z innymi poetami - Jehudą Amichajem, Miłoszem, Zagajewskim). Wiele z przełożonych przez Grönberg wierszy istniało już wcześniej w szwedzkich tłumaczeniach, co pozwala sądzić, że dla tłumaczki (a tym samym dla szwedzkiego czytelnika) ważniejszy od szeroko dyskutowanego w Polsce senilnego okresu twórczości poety jest Herbert sprzed 1989 roku - i jednocześnie wskazać, że lektury polskich poetów przez pryzmat dwudziestowiecznej historii Polski i Europy pozostają dla Szwedów dogodnym kluczem do twórczości niektórych przynajmniej polskich autorów.

W przeciwieństwie do dzieł Herberta twórczość Różewicza jest nadal w Szwecji recypowana bardzo intensywnie. Różewicz przez kilka dziesięcioleci znany był w Szwecji głównie jako dramaturg. Przed 1989 rokiem wydano po szwedzku dwa wybory poezji autora Kartoteki22. W ostatnich trzech dziesięcioleciach ukazało się kilka tomów, prezentujących kolejne poetyckie dokonania autora Rozmowy z księciem, zarówno te dawniejsze, jak i najnowsze. Serię otwiera łączne wydanie przekładu dwóch tomów poety: Relief och Regio [Ptaskorzeźba i Regio] dokonanego przez Bodegårda i Görana Sommardala (1996). Kilka lat później ukazała się książka Professorns kniv och andra dikter [Nożyk profesora i inne wiersze], zawierająca wiersze z wszystkich niemal tomów Różewicza (od Srebrnego ktosu po Nożyk profesora) w wyborze i tłumaczeniu Catherine Berg i Jana Mizerskiego (2003). Specyficzną cechą książki, która nadaje jej charakter autorskiego wyboru, a nie historycznoliterackiej systematyzacji, jest fakt, że wiersze nie zostały zaprezentowane w kolejności chronologicznej. Znalazły się tu między innymi utwory recycling, Walentynki i Sptakane Supermocarstwo (wiersz przedrukowany w szarej strefie, a ogłoszony w „Rzeczpospolitej” dwa dni po zaprzysiężeniu George’a W. Busha na prezydenta Stanów Zjednoczonych - trzeba pamiętać, jak złą prasę miał w Szwecji ten prezydent, zwłaszcza kiedy omawiana tu książka została wydana, a więc dwa lata po zamachu z 11 września ${ }^{23}$ ), i Widziatem Go, i Drzewo, i prawie całość (bez 2 wierszy) nożyka profesora - jednym słowem, w niezbyt obszernym wyborze zmieścił się bardzo różnorodny wybór wierszy. W następnej dekadzie szwedzcy czytelnicy mieli okazję zapoznać się z kolejnym tomem Różewicza - Recycling: nyare dikter [Recycling: wiersze nowsze] w wyborze i tłumaczeniu Grönberg Tomasa Håkansona

22 T. Różewicz, Och så vidare: ett dikturval 1947-1964 [I tak dalej. Wybór wierszy z lat 1947-1964], tłum. J. Kunicki, G. Palm, Stockholm 1966; T. Różewicz, På diktens yta och i dess centrum: valda dikter, tłum. L. Kjellberg, współpraca J. Trypućko, Stockholm 1979.

23 Warto zauważyć, że tytuł tomu wierszy wybranych Różewicza w przykładzie Joanny Trzeciak - Sobbing Superpower (New York 2011) - zaczerpnięty został z tego właśnie wiersza. Gest sięgnięcia do tego utworu przez szwedzką i amerykańską tłumaczkę ma w tych dwóch kontekstach zasadniczo inne znaczenie. 
(2012), zawierającym bardzo obszerny wybór poezji z książek zawsze fragment *recycling, nożyk profesora, szara strefa, wyjście, cóż z tego że we śnie. W ten sposób zaistniała po szwedzku także znaczna część późnej twórczości polskiego poety.

Po 1989 roku zasadniczej zmianie uległa obecność na szwedzkim rynku księgarskim poezji Miłosza, do tego momentu niezbyt imponująca (a przebiegająca w rytm recepcji w świecie anglojęzycznym) ${ }^{24}$. W 1990 roku ukazał się obszerny, pięciusetstronicowy tom Samlade dikter: 1931-1987 (Wiersze zebrane 1931-1987) pod redakcją Nilsa Åkego Nilssona z różnymi tłumaczeniami. Po 2000 roku zainteresowanie Miłoszem stało sie jeszcze wyraźniej zauważalne. W 2004 roku pojawił się tom Det [To] w przekładzie Bodegårda, zawierający wiersze z tomów To oraz Orfeusz i Eurydyka, w 2011 roku kolejny zbiór wierszy w tłumaczeniu Bodegårda i wyborze Bodegårda i Neugera, z przedmową Agnety Pleijel, zatytułowany Ärlig beskrivning [Uczciwe opisanie]. W 2016 roku natomiast wydano monumentalną pozycję pt. Traktater [Traktaty], zawierającą tłumaczenia Traktatu moralnego, Traktatu poetyckiego, Sześciu wyktadów wierszem oraz Traktatu teologicznego z obfitymi komentarzami.

Spośród dzieł „czworga gigantów” ${ }^{25}$ najintensywniej zaistniała na gruncie szwedzkim poezja Szymborskiej ${ }^{26}$, znana w przekładach już od kilku dziesięcioleci $^{27}$. W 1989 roku ukazał się kolejny tom szwedzkich przekładów wierszy poetki, zatytułowany Utopia (wybór i przekład Anders Bodegård, wstęp Lars Kleberg), wznowiony w formie audiobooka w 2005 roku. W „noblowskim” roku 1996 wydano po szwedzku następny, już trzeci, zbiór wierszy Szymborskiej po szwedzku w wyborze i przekładzie Bodegårda Nära ögat [O maty włos] (audiobook 2005). Prawdziwa lawina ruszyła jednak dopiero po 2000 roku. W 2003 pojawił się obszerny wybór poezji Dikter 1945-2002 (przeł. Bodegård), który

24 Poezja Miłosza zaistniała po szwedzku w dwóch wydaniach książkowych stosunkowo późno, gdyż dopiero w latach osiemdziesiątych. W 1980 roku wydano w Uppsali książkę Möte [Spotkanie] (w przekładach Knuta Ahlunda i Evę Bruno z polskiego i angielskiego, co podkreślam, bo Herbert, Szymborska i Różewicz byli tłumaczeni - już wcześniej - od razu z oryginału); w 1985 roku ukazał się w Sztokholmie wybór poezji Miłosza w przekładach i z posłowiem slawisty Nilssona Sången om pärlan och andra dikter [Hymn o perle i inne wiersze].

25 Określenie zbiorcze Miłosza, Różewicza, Herberta i Wisławy Szymborskiej, użyte przez Grönberg i Tomasa Håkansona - por. tychże, Efterord [w:] T. Różewicz, Recycling: nyare dikter, wybór, tłum., I. Grönberg, T. Håkanson, Stockholm 2012, s. 249.

26 Por. analiza tego zjawiska w artykule: M.A. Packalén Parkman, „Somliga gillar poesi... ”om fenomenet Szymborska i Sverige, „Slovo. Journal of Slavic Languages, Literatures and Cultures” 2014, nr 55, s. 149-159. Badaczka sądzi, że czynnikiem decydującym o popularności poezji Szymborskiej w Szwecji jest jej prostota, sprawiająca, że gromadzi ona wokół siebie bardzo szerokie grono czytelników.

27 W przeciwieństwie do poezji Miłosza dzieła Szymborskiej znane były w Szwecji dość dobrze już przed Noblem. Twórczość poetki, obecna w antologii Det nakna ansiktet z 1960 roku, zaprezentowana została szwedzkiej publiczności w 1980 roku wyborem wierszy Aldrig två gånger [Nic dwa razy] w przekładzie Pera Arnego Bodina i Rogera Fjellströma wydanym w Sztokholmie (książkę wznowiono w 1996 roku, a w 2015 roku ukazała się jako audiobook). Czasopismo slawistyki uppsalskiej „Slovo” poświeciło poetce numer monograficzny w 1986 roku. 
po roku (!) wznowiono i który ukazał się niemal równolegle w formie audiobooka (także po zaledwie roku wznowionego). Tomy Ett kolon (2008) [Przecinek], Här [Tutaj] (2009) i Nog nu (2013) [Wystarczy] przetłumaczone zostaty (przez Bodegårda) prawie zaraz po ich opublikowaniu w Polsce i wydawane w formie książkowej (Przecinek także jako audiobook), zaś w 2018 roku wyszły zebrane w jednej książce pt. Sena dikter [Późne wiersze] z posłowiem znanej szwedzkiej pisarki Agnety Pleijel w serii Kvinnliga nobelpristagare i literatur [Kobiety Laureatki Literackiej Nagrody Nobla]. Tę „kobiecą” ramę, tutaj jedynie marginalną, chciałabym wszelako podkreślić, ponieważ kolejne omawiane przykłady skłonią mnie do obszerniejszego komentarza na temat wyrazistego zjawiska czytania poezji polskiej w Szwecji przez pryzmat kategorii feministycznych.

Około 2000 roku nastąpiła w Szwecji pokoleniowa „wymiana” tłumaczy literatury polskiej (pojawiły się nowe i w tej chwili bardzo już ważne postaci, między innymi Grönberg, Lisa Mendoza Åsberg, Stefan Ingvarsson). Mimo to niezbyt częste są sytuacje przyswojenia językowi szwedzkiemu poezji twórców wcześniejszych generacji, uznanych w Polsce, a dotąd w Szwecji nieobecnych: taka sytuacja zdarzyła się poezji Aleksandra Wata i Anny Świrszczyńskiej (o której szerzej za chwilę). O wiele więcej energii poświęcają tłumacze przekładaniu poezji najnowszej.

W 2003 roku ukazała się wspomniana już antologia 17 polska poeter [17 polskich poetów] zredagowana przez Grönberg i Stefana Ingvarssona. Książka prezentuje poetów urodzonych (z kilkoma wyjątkami) w latach sześćdziesiątych XX wieku. Pełna lista autorów to: Dariusz Suska, Marta Podgórnik, Mariusz Grzebalski, Agnieszka Wolny-Hamkało, Marcin Świetlicki, Paweł Marcinkiewicz, Jacek Podsiadło, Marcin Sendecki, Artur Szlosarek, Krzysztof Koehler, Wojciech Wencel, Ewa Sonnenberg, Eugeniusz Tkaczyszyn-Dycki, Andrzej Sosnowski, Marzena Broda, Jarosław Klejnocki, Marzanna Bogumiła Kielar. Są tu więc uwzględnieni zarówno poeci BruLionu, jak i „klasycy”, poezja metafizyczna i humorystyczna. Twórczość poetów nie jest tu zaprezentowana w kolejności chronologicznej, wynikającej z dat urodzin: ta częsta na gruncie szwedzkim (i moim zadaniem bardzo szczęśliwa ${ }^{28}$ ) praktyka sprawia, że czytelnik prowadzony jest raczej tropem pewnych doświadczeń antropologicznych, które odzywają się w poezji, a nie skłaniany do czytania w kluczu porządkująco-historyzującym. Taką ramę pozwala natomiast przyłożyć do zaprezentowanego materiału poetyckiego posłowie Piotra Śliwińskiego, który zapoznaje szwedzkiego czytelnika z rudymentami ustaleń polskiej krytyki literackiej na temat pokolenia poetów-autorów książki.

28 O walorach takiego sposobu prezentowania wierszy, w Szwecji stosowanego niekiedy z dużym powodzeniem, na podstawie antologii szwedzkiej poezji religijnej Insidor pisałam w artykule: K. Szewczyk-Haake, Czym jest poezja, czym jest religia? Kilka uwag o antologiach wspótczesnej poezji religijnej w Polsce i Szwecji, „Rocznik Komparatystyczny” 2016, s. 137-155. 
Jak się jednak miało okazać, zjawiskiem daleko ważniejszym niż omówiona właśnie antologia (która nie doczekała się zresztą znaczniejszej uwagi szwedzkich recenzentów) i wyznaczającym niejako linię rozwoju recepcji polskiej poezji w Szwecji jest jej swoista kontynuacja w postaci wyboru wierszy polskich poetek. W 2008 roku ukazała się antologia pod tytułem zaczerpniętym z liryku Krystyny Miłobędzkiej ogłoszonego w jej tomie Po krzyku: Jag i första och sista person. 20 polska kvinnliga poeter [Ja w pierwszej i ostatniej osobie. 20 polskich poetek]. Jak się zdaje, w powstaniu tej antologii miała swój udział (typowo skandynawska?) wiara w to, że za pomocą przyjęcia pewnych rozwiązań społecznych (na przykład parytetów w polityce i biznesie) można skutecznie kształtować nawyki społeczne, a także w dziedzinie kultury. Sądząc po odzewie recenzenckim, jaki uzyskała antologia wierszy polskich poetek ${ }^{29}$ (przekraczającym znaczenie rezonans uzyskany przez tom omawiany wcześniej), koncept edytorski nie był chybiony, wręcz przeciwnie.

Zasadniczo odmienna perspektywa autorów wyboru zarysowana jest już w otwierających obie antologie przedmowach. We wstępie do Jag i första och sista person redaktorzy piszą, że „Praca nad tą książką była w pewnym sensie odkrywaniem ziemi dziewiczej - zasadniczo brakuje bowiem podobnej antologii po polsku" ${ }^{30}$. Akcentują fakt, że ich przedsięwzięcie ma charakter, ni mniej, ni więcej, dbania o równość płci - tam, gdzie nie znajduje ona miejsca:

Poetki są w Polsce czytane, a ich utwory ukazują się w coraz to nowych wydaniach, lecz w historii literatury często spychane są do przypisów. Mimo istnienia wielu znakomitych poetek pisanie wierszy jawi się w Polsce jako zajęcie typowo męskie ${ }^{31}$.

Także ten wybór liryków proponuje ciekawą kolejność zapoznawania się z dziełami poetek - niechronologiczną, a zatem ułatwiającą lekturę nakierowaną raczej na odkrywanie doświadczenia kobiecego niż generacyjnego albo meandrów historii literatury polskiej czy historii w ogóle (czytelnik na przykład nie może, o ile nie podejmie intencjonalnie takiego wysiłku, zaczerpnąć z antologii poetyckiego obrazu drugiej wojny światowej; tematyka ta jest tu oczywiście obecna, lecz pozostaje rozsiana w całej książce). Tom otwiera Miłobędzka, potem prezentowane są kolejno Podgórnik, Kielar, Świrszczyńska, Maria Pawlikowska-Jasnorzewska, Joanna Salamon, Halina Poświatowska, Małgorzata Hillar, Anna Janko, Sonnenberg, Anna Kamieńska, Wolny-Hamkało, Kazimiera Iłłakowiczówna, Urszula Kozioł, Adriana Szymańska, Zuzanna Ginczanka, Julia Fiedorczuk, Ludmiła Mariańska, Marta Grundwald, Julii Hartwig. Wiersze

29 Wybrane głosy recenzenckie przywołane zostały w artykule: M.A. Packalén Parkman, „Niektórzy lubia poezję”- ale czy koniecznie polską i w Szwecji?..., dz. cyt., s. 44-46.

30 I. Grönberg, S. Ingvarsson, Förord [w:] Jag i första och sista person. 20 polska kvinnliga poeter, red. I. Grönberg, S. Ingvarsson, Stockholm 2008, s. 8, tłum. K.S.H.

31 Tamże, s. 7. 
zawarte w książce dotąd nie były publikowane po szwedzku. W antologii nie uwzględniono wierszy Szymborskiej i Lipskiej, gdyż te dwie autorki miały już w roku ukazania się antologii odrębne tomiki w tym języku.

W posłowiu napisanym przez sztokholmską slawistkę Renatę Ingbrant (autorkę pisanej z perspektywy feministycznej monografii poezji Świrszczyńskiej ${ }^{32}$ ) nacisk położony został na fakt, że choć obecne $\mathrm{w}$ antologii poetki różnią się między sobą, to łączy je - jak pisze badaczka - „sposób, w jaki korzystają z języka, i związanej z nim tradycji lirycznej" ${ }^{33}$.

Niektóre z poetek uwzględnionych w antologii należą, jak pisze Ingbrant, do „liryki kobiecej”, czyli jej zdaniem takiej, w której płeć stanowi ważny punkt wyjścia dla pisarki i jej dzieł. W ich poczet zalicza badaczka Pawlikowską, Poświatowską, Hillar, Kamieńską, Marjańską i Świrszczyńską, i im poświęca w posłowaniu najwięcej miejsca. Wyróżnia także drugi biegun kobiecego pisania, „ostatniej osoby”, w istocie bezosobowy, próbujący perspektywy z lotu ptaka i nieuwzględniający indywidualności ,ja” kobiecego (ani żadnego innego). Tu plasuje badaczka poezję Hartwig, także Szymborskiej i Kozioł. Wskazuje też na nieuniknione napięcie, jakie w poezji polskiej istnieje między (kobieca) potrzebą ekspresji tego, co indywidualne, a (specyficzną dla zanurzonej w rozważaniu meandrów historii polskiej tradycji lirycznej) predylekcją do nadawania niepomiernie wyższej rangi przeżyciom pokoleniowym.

Redaktorzy antologii, sięgając do wyrazistego klucza oddzielającego tradycję pisarską „poetów” i „poetek”, wpisują się w oczywisty sposób w charakterystyczne dla Szwecji (szerzej: Skandynawii) poszukiwanie równości między płciami i docenienie głosów kobiecych - przez ich wyodrębnienie. Jest to tradycja bardzo dawna, aż dziw, że w lekturze obcych kultur dochodzi do głosu $\mathrm{z}$ bez małą wiekowym opóźnieniem ${ }^{34}$. Literaturę tworzoną przez kobiety jako odrębne i ważne zjawisko literackie bada się w Skandynawii systematycznie od lat sześćdziesiątych XX wieku, a w polonistyce szwedzkiej tendencja ta silnie zaznacza się od lat mniej więcej dwudziestu, kiedy o literaturze polskiej (co w perspektywie rynku translatorskiego ważne - także najnowszej) pisała Packalén,

32 R. Ingbrant, From "Her” Point of View: Woman's Anti-World in the Poetry of Anna Świrszczyńska, Stockholm 2007.

33 Taż, Efterord [w:] Jag i första och sista person..., dz. cyt., s. 231, tłum. K.S.H.

34 Od lat osiemdziesiątych XIX wieku w Skandynawii powstawały organizacje kobiece, mające na celu między innymi zrównanie praw obywatelskich kobiet i mężczyzn. Skandynawia stała się regionem, gdzie kobiety jako pierwsze na świecie mogły brać udział w wyborach parlamentarnych (w Finlandii już w 1906 roku). Tradycji tych w XX wielu bynajmniej nie zaprzepaszczono, a wręcz przeciwnie - Skandynawia zyskała potwierdzenie swego statusu jako regionu wyemancypowanych kobiet, aktywnych zawodowo i społecznie, których pozycja w kulturze i życiu publicznym pozostała wyjątkowo silna. Towarzyszyła temu zjawisku wysoko rozwinięta samoświadomość: studia o ruchu kobiecym, dokumentujące jego historię i badające jego idee, powstają w Skandynawii od lat trzydziestych XX wieku. 
używając perspektywy genderstudies. W tym samym porządku należy również widzieć wspomnianą pracę Ingbrant o Świrszczyńskiej.

W jakiś sposób echem dysertacji Ingbrant była publikacja w 2014 roku obszernego wyboru poezji Świrszczyńskiej w przekładzie Grönberg i Åsberg. W posłowaniu Ingbrant szczególny nacisk został położony na te elementy twórczości autorki Jestem baba, które czynią z niej znakomity materiał dla studiów nad płciowością w literaturze. Taka rama interpretacyjna nie pozostała bez echa. Kilkoro recenzentów, jak zwróciła uwagę Packalén, „podchwyciło (...) cenne aspekty poezji Świrszczyńskiej, te właśnie, które czynią jej poezję wręcz unikalną w historii poezji polskiej tego okresu: mianowicie zagadnienia związane z cielesnością i seksualnością" ${ }^{35}$.

Umieszczanie twórczości polskich poetek w porządku feministycznym na gruncie szwedzkim, choć jego datowanie jest całkiem niedawne, wydaje się zabiegiem okrzepłym. W 2017 roku ukazała się książka prezentująca liryczne dokonania Julii Fiedorczuk Syre [Tlen] (zawierający wybór z wszystkich dotychczas ogłoszonych tomów poetki) - oba w wyborze i przekładzie Grönberg. W posłowiu tłumaczka pisze o Fiedorczuk, że jest wykładowczynią literatury amerykańskiej i „Jej głos jest wyraźnie słyszalny we współczesnej polskiej debacie literackiej i ma wyraźny akcent feministyczny" ${ }^{36}$. Wygląda na to, że przymiotnik ten traktowany jest w Szwecji jako nie tylko pochwalny, ale także zaskarbiający potencjalnych czytelników i czytelniczki, zaś głos „polskich kobiet” (czyli „polskich poetek”) jest słuchany z większą uwagą niż głos polskich poetów - może również dlatego, że los tych ostatnich budzi mniej obaw ${ }^{37}$. Zarazem można chyba uznać, że historyczny klucz lektury poezji polskiej, który przez dziesięciolecia miał w Szwecji pozycję dominującą, kwestionowany od lat osiemdziesiątych, został zamieniony na klucz feministyczny. Co może zaskakiwać - zwłaszcza tę część polskiej krytyki literackiej, z której męskocentrycznym punktem widzenia polemizowała w swoim czasie Packalén, stając w obronie młodych polskich pisarek ${ }^{38}$.

35 M.A. Packalén Parkman, „Niektórzy lubią poezję”- ale czy koniecznie polskq i w Szwecji?..., dz. cyt., s. 46 - tu przytoczone głosy między innymi Evy Ström i Sebastiana Lönnlöva.

36 I. Grönberg, Efterord [w:] J. Fiedorczuk, Syre, wybór, tłum. I. Grönberg, Stockholm 2017, s. 95, tłum. H.S.H.

37 Por. fragment recenzji antologii Jag i första och sista person: „W kraju, gdzie strajkujące pielęgniarki jeszcze tak niedawno zostały brutalnie potraktowane przez policję, nie brakuje oczywiście tematów do obrazowania ani też przemocy do pokonania”. M. Bergqvist, Tvära kast finns i polsk poesi, „Norrbottenkuriren”,12.08.2008 (cyt. za: M. Packalén Parkman, „Niektórzy lubia poezje” - ale czy koniecznie polska i w Szwecji?..., dz. cyt., s. 45, tłum. M.P.P.).

38 M.A. Packalén, „Komża i majtki”, czyli prowokacja tradycji w polskiej literaturze wspótczesnej, „Teksty Drugie” 2004, nr 6, s. 157-173. 


\section{Bibliografia}

Berg C., Efterord [w:] T. Różewicz, Professorns kniv och andra dikter, wybór, tłum. C. Berg, J. Mizerski, Stockholm 2003.

Det kämpande Polen, red. N. Żaba, M. Hansson, Stockholm 1942.

Det nakna ansiktet, N.A. Nilsson, Stockholm 1960.

Du måste vittna. Poesi och reportage frän Polen, red. N.Å. Nilsson, Stockholm 1981.

Grönberg I., Efterord [w:] J. Fiedorczuk, Syre, wybór, tłum. I. Grönberg, Stockholm 2017.

Grönberg I., Efterord [w:] T. Dąbrowski, Idag har jag åter hört tystnaden efter mig. Dikter, wybór, tłum. I. Grönberg, Malmö 2017.

Grönberg I., Efterord [w:] Z. Herbert, Inskrifter: valda dikter 1956-1998, wybór, tłum. I. Grönberg, Lund 2013.

Grönberg I., Förord [w:] 17 polska poeter, red. I. Grönberg, Stockholm 2003.

Grönberg I., Håkanson T., Efterord [w:] T. Różewicz, Recycling: nyare dikter, wybór, tłum. I. Grönberg, T. Håkanson, Stockholm 2012.

Grönberg I., Ingvarsson S., Förord [w:] Jag i första och sista person. 20 polska kvinnliga poeter, red. I.Grönberg, S. Ingvarsson, Stockholm 2008.

Handberg P., Förord [w:] A. Wat, Bokslut, wybór, tłum. P. Handberg, Stockholm 2006.

I stridsvagnens spair: dikter 1956-1965, tłum. E. Lindegren, E. Mesterton, Stockholm 1965.

Ingbrant R., Efterord [w:] Jag i första och sista person. 20 polska kvinnliga poeter, red. I. Grönberg, S. Ingvarsson, Stockholm 2008.

Ingbrant R., From „Her” Point of View: Woman's Anti-World in the Poetry of Anna Świrszczynska, Stockholm 2007.

Kleberg L., Efterskrift [w:] A. Zagajewski, Ode till mångfalden och andra dikter, wybór, tłum. A. Bodegård, L. Kleberg, Norstedts, Stockholm 1987.

Miłosz C., Möte, tłum. K. Ahlund, E. Bruno, Uppsala 1980.

Miłosz C., Sången om pärlan och andra dikter, tłum. N.Å. Nilsson, Stockholm 1985.

Packalén M.A., "Komża i majtki”, czyli prowokacja tradycji w polskiej literaturze wspótczesnej, „Teksty Drugie” 2004, nr 6.

Packalén M.A., Polska poezja wspótczesna w Szwecji, „Polonistyka” 1999, nr 2.

Packalén M.A., Under två kulturers ok. Allmogeskildringar i den polska och svenska 1880- och 1900-talslitteraturen, Uppsala 2001.

Packalén Parkman M.A., „Niektórzy lubia poezje” - ale czy koniecznie polska i w Szwecji?..., „Slovo. Journal of Slavic Languages, Literatures and Cultures” 2017, nr 58.

Packalén Parkman M.A., „Somliga gillar poesi...” - om fenomenet Szymborska $i$ Sverige, „Slovo. Journal of Slavic Languages, Literatures and Cultures” 2014, nr 55. 
Rapport frän en belägrad stad och andra dikter, tłum. A. Pleijel, D. Bronski, współpraca E. Mesterton, Stockholm 1985.

Różewicz T., Och så vidare: ett dikturval 1947-1964, tłum. J. Kunicki, G. Palm, Stockholm 1966.

Różewicz T., På diktens yta och $i$ dess centrum: valda dikter, tłum. L. Kjellberg, współpraca J. Trypućko, Stockholm 1979.

Różewicz T., Sobbing Superpower, tłum. J. Trzeciak, przedmowa E. Hirsch, New York 2011.

Så länge vi leva. Polsk lyrik 1939-1945, „Svio Polonica” 1946.

Szewczyk-Haake K., Czym jest poezja, czym jest religia? Kilka uwag o antologiach wspótczesnej poezji religijnej w Polsce i Szwecji, „Rocznik Komparatystyczny” 2016.

Szewczyk-Haake K., Ślad czotgu i sala zwierciadet. O spotkaniu dwóch poetów i ważkich decyzjach redaktorów, „Acta Sueco-Polonica” 2008-2009, nr 15.

Szulc Packalén M., Pokolenie 68. Studium o poezji polskiej lat siedemdziesiątych, Uppsala 1987.

Szymborska W., Aldrig två gånger, tłum. P.A. Bodin, R. Fjellström, Stockholm 1980.

Trotzig B., Att vara i mitten utan att gråta [w:] tejże, Porträtt. Ur tidshistorien, Stockholm 1993.

Trotzig B., Porträtt. Ur tidshistorien, Stockholm 1993.

Uggla A.N., Polska liryka w Szwecji po roku 1939, „Slovo. Journal of Slavic Languages, Literatures and Cultures" 1981, nr 20. 